\title{
APONTAMENTOS PARA UMA ABORDAGEM DIALÉTICA DAS RELAÇÕES CIDADE-CAMPO: DO MODELO CLÁSSICO AOS NOVOS DESAFIOS
}

\author{
APONTAMIENTOS PARA UNA ABORDAGEN DIALÉTICA DE LAS \\ RELACIONES CIUDAD-CAMPO: DE LO MODELO CLÁSICO A LOS \\ NUEVOS DESAFÍOS
}

\author{
NOTES FOR A DIALECTIC APPROACH ON TOWN-COUNTRY \\ RELATIONS: FROM THE CLASSICAL MODEL TO THE NEW \\ CHALLENGES
}

\author{
Giancarlo Livman Frabetti \\ Mestrando em Geografia Humana pela Universidade de São Paulo (USP) e bolsista \\ da Fundação de Amparo à Pesquisa do Estado de São Paulo (FAPESP). \\ xepah@hotmail.com
}

\section{Resumo}

A análise da relação cidade-campo nas ciências sociais é constantemente deduzida a partir da aplicação de um modelo unívoco de interpretação. Por isso, a sua importância para a compreensão dos fenômenos sociais vem sendo negligenciada. Este artigo visa identificar subsídios teóricos que nos permitam pensar a complexidade das relações entre cidade e campo. Para isso, partiremos das bases clássicas sobre o debate, a partir das quais derivam as formulações que advogam o fim das contradições nestas relações. Uma vez demonstrado que a teoria do desenvolvimento desigual do capitalismo refuta essas teses, finalizaremos com a análise do caso brasileiro, sugerindo uma variedade de possibilidades de se conceber dialeticamente as contradições entre campo e cidade.

Palavras-chave: Cidade, Campo, Relação cidade-campo, Desenvolvimento desigual, Desenvolvimento rural.

\section{Resumen}

La análisis de la relación ciudad-campo en las ciências sociales és constantemiente deducida a partir de la aplicación un modelo unívoco de interpretación. Por eso, su importância para la compreensión de los fenômenos sociales ha sido descuidada. Esto artículo visa identificar subsídios teóricos que nos permitan pensar la complejidad de las relaciones entre ciudad y campo. Para eso, partiremos de las bases clásicas del debate, a partir de las quales derivam las formulaciones que advogam el fin de las contradicciones en estas relaciones. Una vez demonstrado que la teoria del desarollo desigual de lo capitalismo refuta estos teses, nosotros finalizaremos con la análisis de el caso brasileño, proponendo una variedad de possibilidades de se concebir dialeticamente las contradicciones entre el campo e la ciudad.

Palabras claves: Cuidad, Campo, Relación cuidad-campo, Desarrollo desigual, Desarrollo Rural 


\begin{abstract}
Social sciences constantly draw town-country relations analysis from a univocal interpretative model. Thus, its meaning for the comprehension of social phenomenons has been neglected. The present article searches for theoretical subsidies which allow us to think about how complex town-country relations are. In order to fulfill this objective, we'll start from the classical basis of the debate, which has influenced formulations announcing the end of contradictions concerning these relations. Once we have shown that the theory of capitalism's uneven development refuses such thesis, we'll be led to the analysis of the Brazilian case, then suggesting a range of possibilities to conceive the dialectic analysis of town-country relations.
\end{abstract}

Keywords: City, Country, Town-country Relation, Uneven Development, Rural Development.

\title{
Contra o pressuposto do fim das contradições na relação cidade-campo
}

As dificuldades para, a princípio, discutir teoricamente e, depois, tratar como uma totalidade concreta o campo e a cidade, mostram-se logo evidentes quando lembramos das cisões ocorridas no desenvolvimento do trabalho intelectual. Para citar somente dois exemplos, tanto a geografia (com sua geografia agrária e sua geografia urbana, dentre tantas outras) como a sociologia (igualmente dividida entre sociologia rural e sociologia urbana) empreendem esforços separados no interior das próprias disciplinas para tratar distintamente destas realidades. Trata-se de um caminho que vem deixando uma lacuna no pensamento, que poucos autores fizeram verdadeiro esforço para compreender, qual seja, a análise de como se relacionam esses espaços, e qual o peso desta relação na reprodução (e mesmo na superação) da ordem social vigente.

Argumentaremos, neste artigo, que a dificuldade para identificar e problematizar as tensões que envolvem a cidade e o campo no presente resulta de limitações nas próprias tradições teóricas das ciências sociais. Autor pioneiro no tratamento da questão agrária no Brasil, Alberto Passos Guimarães atribuía às relações sociais no campo um caráter feudal ou semifeudal, enfatizando a característica latifundiária da propriedade rural brasileira. Já Caio Prado Júnior chamava atenção para a racionalidade empresarial do latifúndio agrícola nos diversos momentos da história brasileira, negando o caráter semifeudal das relações sociais e enfatizando o papel do assalariamento na agricultura (COUTINHO, 2001). Os processos sociais no Brasil, para esta última corrente teórica, 
combinariam, portanto, modernização e conservação, uma "revolução pelo alto" na passagem para o capitalismo. Poderíamos assim dizer que, nesta corrente teórica da qual Prado Jr. é fundador, há uma tendência a sublinhar a permanência do velho em contraposição ao avanço do novo (este, definindo o curso necessário da História). Daí a recorrente idéia de que faltaria ao Brasil superar esta permanência do arcaico, de modo que fosse possível, enfim, haver a polarização das classes sociais no país, completando seu processo de modernização capitalista.

José de Souza Martins (1998) tece a seguinte crítica a essa perspectiva: a discussão da passagem para o capitalismo no Brasil feita pelo Partido Comunista foi remetida, por Caio Prado, mas também por Florestan Fernandes, entre outros, ao argumento de que as relações de produção no campo não eram formalmente feudais e, portanto, só podiam ser formalmente capitalistas. Para esses autores clássicos, e para muitos outros que de suas teorias derivam, haveria sem dúvida a apropriação do excedente sob forma de mais-valia, embora o salário proviesse de formas monetárias e não monetárias. O problema teórico dessa argumentação está, para Martins, em tratar as relações de trabalho como "formas disfarçadas de relações capitalistas" - relações definidas a priori, e que caíram num formalismo oposto ao do modelo do Partido Comunista. Uma polarização ideológica derivada, na verdade, dos dilemas e impasses políticos de então.

Segundo MARTINS (1981), ainda não foram resolvidas as contradições resultantes da questão da propriedade da terra no Brasil agrário, situação que nos coloca uma outra questão. Se estamos diante da reprodução capitalista de relações de produção não capitalistas no campo, se os "vestígios arcaicos da formação econômica brasileira" não foram até hoje eliminados, é possível deixar de lado a mediação que as relações entre cidade e campo exercem no processo histórico deste país?

Acrescentamos que, diante deste debate clássico nas ciências sociais, as relações entre cidade e campo na especificidade do processo histórico brasileiro foram somente inferidas e, por isso, tiveram a apreensão de sua complexidade restrita à hipótese teórica de que, com a expansão das relações capitalistas, haveria sem dúvida a urbanização da população brasileira, bem como de sua economia. A terra e o trabalho no campo responderiam prontamente às leis do capital, de modo que a verdadeira contradição social, entre proletariado e burguesia, se daria nas cidades. Enfim, a explicação da relação cidade-campo, no Brasil, é deduzida logicamente, como se fosse um espelho da 
situação historicamente circunscrita que Marx abordou, por exemplo, em seu capítulo sobre a acumulação primitiva no Livro I de $O$ Capital.

Para argumentarmos no sentido de que a relação cidade-campo hoje é indevidamente pensada como um modelo acabado, paradoxalmente tomado de uma obra que não propunha a criação de tais modelos, resgataremos inicialmente, neste artigo, o pensamento marxiano em certos trechos da A Ideologia Alemã. Nesse texto, ao formular o materialismo histórico, Marx e Engels utilizam como instrumental o conceito de divisão do trabalho para explicar a formação da propriedade privada e o surgimento de novas relações sociais cada vez mais mediadas por abstrações, demonstrando as contradições que viriam a engendrar o modo capitalista de produção. A relação entre campo e cidade é reconstituída de modo a resultar em uma sociedade na qual a divisão do trabalho atinge seu máximo desenvolvimento: a riqueza deixa de ser sobretudo a agrária e o capital deixa de ser imobiliário, encerrando-se assim as tensões entre a burguesia e os senhores de terra. Trata-se, no entanto, conforme exemplificamos nesta breve exposição inicial sobre a questão agrária brasileira, de uma análise processual que posteriormente será tomada como modelo, ao qual denominaremos modelo clássico de transformações nas relações cidade-campo, e que se mostrará influente em todo o debate posterior (ou mesmo na virtual ausência do debate) acerca da relação cidadecampo.

Em seguida, buscaremos mostrar que as concepções dualistas nas ciências sociais resultam do aniquilamento do tratamento dialético das relações cidade-campo. Tomaremos como exemplo a sociologia urbana e a sociologia rural que, seja enfatizando as diferenças entre a comunidade e a sociedade, seja enfatizando as interrelações entre o arcaico e o moderno como dois extremos de um continuum, seguiram também o caminho de admitir precipitadamente o fim das contradições na relação cidade-campo.

Indicaremos, contudo, que a teoria da produção não-capitalista do capital, apoiada na concepção de sujeição da renda da terra ao capital, nos lega a necessidade de pensar o papel político do campo e do campesinato na sociedade brasileira. Diante do que nos sugere esta linha teórica, tornam-se evidentes tanto a peculiaridade da reprodução das relações sociais no campo quanto a tensão que esta reprodução exerce sobre o ideal de modernidade que emana dos centros de decisão (e consumo) no Brasil. O campo e o campesinato, dentro desta perspectiva a qual buscamos aqui nos 
aproximar, devem ser vistos como contradições intrínsecas ao desenvolvimento econômico, e não como aberrações (ou sobras de tempos pretéritos) na formação social brasileira.

Finalmente, indicaremos que o debate realizado a partir de categorias como cidade e campo, rural e urbano, atualmente incorre em assumir como verdadeira a tese de que, em países como o Brasil, o desenvolvimento do mercado interno teria resolvido a contradição existente entre a grande expressão social e demográfica do campesinato e o processo de modernização econômica. De um lado, os "complexos agro-industriais" teriam finalmente efetuado a urbanização do campo, estando os empregos da população rural concentrados no setor terciário e não mais na agricultura (GRAZIANO DA SILVA, 1996). De outro lado, a "agricultura familiar" nos países de primeiro mundo constituiria um exemplo de como o trabalho familiar no campo deveria ser integrado aos "mercados perfeitos" (alinhado, portanto, com a técnica, com o mercado e com capital financeiro), e não mais orientado segundo os objetivos intrínsecos à economia doméstica, nem segundo o modo de vida peculiar do camponês (ou seja, seu caráter de part society) (ABRAMOVAY, 1992). Mais uma vez, o pensamento sobre questões que envolvem cidade e campo coloca os trabalhadores rurais como meros figurantes de uma história que se conta a partir das decisões e dos interesses organizados, materializados e irradiados a partir das grandes metrópoles (com seus entrepostos e centros consumidores, com seus centros financeiros e sua política).

O objetivo deste texto é o de apontar e criticar uma grande tendência das ciências sociais que, ao influenciar diferentes perspectivas teóricas, veio obscurecendo a possibilidade de fugirmos à teleologia evolucionista que advoga precipitadamente o fim das contradições nas relações cidade-campo. Entendemos que, antes de tomar como certo o fim de qualquer possibilidade das forças sociais no campo exercerem oposição ao rumo aparentemente inexorável da modernização econômica, é necessário recuperar a discussão em torno de categorias como cidade e campo, rural e urbano, a fim de que, com a ampliação do debate, surjam mais trabalhos dando conta de investigar as nuances, as tendências contrárias, as tensões e, assim, a complexidade desta relação que aqui nos intriga. 


\section{A relação cidade-campo na economia política e a análise do modelo clássico das transformações nesta relação}

Partindo das bases lançadas no debate da economia política sobre as relações entre cidade e campo, recuperaremos os fundamentos da concepção materialista e dialética acerca desta questão. Marx e Engels (1977), em A Ideologia Alemã, propõem como ponto de partida para a interpretação da ação dos homens a capacidade de produção dos seus próprios meios de vida. Para criar as condições materiais de sua existência, os indivíduos, com seu trabalho, utilizam e, assim, transformam o estado determinado em que se encontram as forças produtivas. Produzem, dessa forma, sua própria vida social, na medida em que o resultado desta produção engendra uma ruptura, qual seja, a maior divisão do trabalho, bem como o aprofundamento do intercâmbio (material e espiritual) entre as sociedades. Como forma de sustentação dessas proposições fundamentais do materialismo histórico, Marx e Engels também apresentam uma interpretação acerca da origem de uma das mais antigas e persistentes formas de diferenciação social existentes, "um ponto cuja importância na historicidade a história dos historiadores nem sempre soube reconhecer" (LEFEBVRE, 1971: 41):

A divisão do trabalho no interior de uma nação leva, inicialmente, à separação entre o trabalho industrial e comercial, de um lado, e o trabalho agrícola, de outro, e com isso, à separação da cidade e do campo e à oposição de seus interesses (MARX, 1977: 29. Grifo nosso).

Campo e cidade, na tradição do materialismo histórico, se distinguem e interrelacionam de acordo com o modo pelo qual se divide e organiza o trabalho social e, assim, se estabelecem as formas de propriedade, fundamentalmente a propriedade da terra. São partes de um todo, constituídas por relações sociais e de apropriação dos recursos disponíveis e desigualmente distribuídos no espaço. Constituem, portanto, formas sociais territorializadas que passam, elas mesmas, a funcionar enquanto forças produtivas, impulsionando o desenvolvimento das sociedades em geral, mas entrando como mediação no acirramento das contradições no interior dessas mesmas sociedades na medida em que os processos (conteúdos) que criam e reproduzem tais formas sociais entram em tensão sob circunstâncias historicamente determinadas. Apesar da origem comum, ambas as formas tornam-se fenômenos em um determinado momento no qual o 
desenvolvimento das forças produtivas no interior de um grupo (ou nação) acaba por gerar uma ruptura social, cujas partes passam a se opor mutuamente segundo o sentido de seus interesses: a relação cidade-campo tem, assim, na sua gênese, um caráter de complementaridade forçada entre desiguais (ou seja, de "oposição dos interesses", conforme o trecho supracitado). Forjam-se o "animal rural" e o "animal urbano", a "expressão mais crassa da subsunção do indivíduo à divisão do trabalho, a uma determinada atividade que lhe é imposta" (MARX, 1977: 78).

SINGER (1979), interpretando esta passagem a respeito da separação original entre campo e cidade, afirma que, enquanto comunidades ecológicas, estas duas formas são um efeito secundário (superestrutural) do processo social fundamental para a formação das sociedades de classe, que é a participação diferenciada dos homens no processo de produção e distribuição (SINGER, 1979: 13), permitindo a transferência do sobreproduto agrícola da base da sociedade para um grupo dominante livre da obrigação de produzir e, portanto, capaz de se isolar espacialmente do restante da sociedade. A primeira divisão do trabalho entre cidade e campo teria resultado, por isso, da criação de um excedente na produção agrícola e da separação de uma classe dominante dedicada à organização da sociedade a fim de se apropriar do sobreproduto. Por isso, para este autor, não faz sentido explicar a sociedade a partir da relação cidade-campo: ao contrário, são as relações de classe que explicariam a distinção e o intercâmbio entre ambos. Todavia, apontamos aqui um contraponto necessário: estes resultados "superestruturais" (ou seja, o campo e a cidade) devem ser compreendidos dialeticamente como expressão concreta de uma das mais antigas e persistentes rupturas no processo histórico, a qual compõe a estrutura mais elementar da base material das sociedades, indispensável, portanto, para sua reprodução. Daí a possibilidade de pensarmos, nas mais variadas conjunturas, contradições em cuja origem está a separação e a oposição dialética entre campo e cidade: esta relação tem sido condição para a reprodução da ordem, bem como para o surgimento de crises, nas mais diversas formações sociais.

Dessa discussão inicial, extraímos que o campo e a cidade são produtos da ação das sociedades humanas, mas, simultaneamente, são produtos que comportam as próprias condições materiais da reprodução de sujeitos sociais que eventualmente podem se encontrar em oposição no interior dessas mesmas sociedades. Via de regra, o campo representa o isolamento e a dispersão e a cidade, o encontro e a aglomeração, a 
centralidade. Eis que essas características são forças produtivas combinadas e investidas no processo mais amplo de reprodução e transformação da totalidade social.

De maneira historicamente determinada no modo de produção da Antigüidade, as trocas (materiais e imateriais) efetuadas a partir das configurações territoriais distintas entre campo e cidade sustentaram o surgimento do poder centralizado, representando a divindade, ou o poder separado (como denomina DEBORD, 2003), constituindo aspectos articulados de um processo social mais geral que é o próprio surgimento da civilização, ou a chamada Revolução Urbana (PINSKY, 1987). Tendo surgido da divisão do trabalho dada com a constituição de uma classe que organiza o trabalho social para dele não só extrair o excedente, como afirma Paul Singer (1979), mas para impor e reproduzir uma ordem social centralizada no poder separado, a cidade e o campo, a partir dos seus conteúdos sociais, já entram para a história como forças em tensão. Tal tensão mostra-se, às vezes, violenta (criadora de realidades totalmente novas), outras vezes revela uma cooperação realizada horizontalmente, mas nunca livremente, já que cidade e campo sempre foram a expressão das oposições e desigualdades nas relações entre os sujeitos sociais. As formas de cooperação e intercâmbio ou as diferenças de interesse entre os sujeitos históricos aos quais as formas cidade e campo podem corresponder, bem como a relativa condição de vantagem ou desvantagem na disputa por esses interesses, nos conduz à idéia de que entre campo e cidade pode eventualmente haver contradição (criadora de superação) ou cooperação funcional (que, todavia, reforçamos, parte de uma cooperação forçada):

O conflito (dialético) entre a cidade e o campo não exclui certa unidade e, o que é mais, inclui-a até, como em todo o processo dialético. Há, portanto, uma dificuldade de análise: apreender a relação exata entre a unidade e a contradição, o momento em que o conflito se resolve (quer gerando novas diferenças, quer retrocedendo para um declínio mais ou menos prolongado que gera a indiferença) (LEFEBVRE, 1972: 56).

Assim, segundo o modelo clássico que analisa primeiramente a relação cidadecampo nas sociedades denominadas antigas, temos que nelas as cidades eram, sobretudo, políticas; apareciam eminentemente como consumidoras, enquanto o campo era o lugar da produção por excelência. Toda a organização social das civilizações da Antigüidade se deu a partir da cidade e do seu território relativamente pequeno, de onde emanava o poder centralizador de domínios e mão-de-obra escrava. Essa cidade 
política, portanto, organizava e explorava um território agrário com camponeses e pastores; mas, "no seio deste desenvolvimento urbano, o único conflito de importância era o que opunha escravos e cidadãos. Esta era a única relação de classes" (LEFEBVRE, 1972: 41). Por isso:

As revoltas dos escravos, inteiramente legítimas, estavam antecipadamente vencidas. E porquê? Porque estava antecipadamente garantido o domínio da cidade política sobre os campos vizinhos, implícito na relação 'cidade-campo'. (...) as contradições da cidade antiga eram destrutivas, e não criadoras de superação (LEFEBVRE, 1972: 43-44).

Com o declínio dessas civilizações antigas e, em particular, durante a queda do Império Romano, inaugurou-se uma modalidade de dominação territorial na qual passou a ocorrer justamente o contrário do que se dava antes: o poder fragmentou-se e se distribuiu por uma grande extensão de terras e, pela proteção militar, assumiu o controle tanto sobre pequenos territórios, quanto sobre os servos e seu trabalho, tendo, assim, se originado no campo a estrutura social conhecida como feudalismo. Estrutura dirigida simultaneamente "contra a classe produtora dominada (a dos camponeses)" e "contra a cidade (contra os seus habitantes, os 'burgueses' que se entregam ao comércio e às trocas)" (LEFEBVRE, 1972: 42), já que a estrutura social das corporações de ofício refletia não uma divisão técnica do trabalho, mas tinha o sentido de dominação pessoal. Forjava-se, assim, uma "dupla luta de classes".

Luta essa que levou ao nascimento da revolução urbana e do Estado Monárquico na Idade Média Européia. Com isso, "a cidade, até então subordinada à estrutura feudal, conquista o domínio e simultaneamente destrói a estrutura feudal, que incorpora em si, transformando-a" (LEFEBVRE, 1972: 42). Assim, mesmo que estas duas formas (propriedade fundiária no campo, propriedade corporativa nas cidades) estivessem baseadas em limitadas forças produtivas e relações sociais - "agricultura ainda rudimentar, indústria ainda artesanal, intercâmbio ainda pouco intenso, divisão do trabalho pouco profunda" (LEFEBVRE, 1972: 43) - este foi um momento assinalado como o primeiro em que as próprias classes dominantes da cidade e do campo realmente assumiram, como tais, parte numa relação contraditória:

(...) na Europa da Idade Média (tendo o cuidado de excluir o caso do 'modo asiático de produção') a relação cidade-campo torna-se conflituosa. (...) a cidade e a burguesia medieval tiveram de lutar para 
conseguir a supremacia política e a capacidade de explorar economicamente os campos, tomando o lugar dos senhores fundiários na recolha do sobretrabalho (...). No decurso desse processo a cidade gera algo diferente, algo que a ultrapassa: no plano econômico, gera a indústria; no plano social, gera a propriedade de bens móveis (...); no plano político, finalmente, gera o Estado. Esse o resultado da primeira grande luta de classes e das formas sociais na Europa: cidade contra campos, burguesia contra feudalismo, propriedade de bens móveis e propriedade privada contra propriedade fundiária e comunitária (LEFEBVRE, 1972: 44).

Contudo, segundo esta análise do modelo clássico, não havia ainda se completado a primazia da cidade sobre o campo, pois considera-se que, na cidade medieval, havia capital sem capitalismo, assim como havia trabalhadores, mas não proletariado: não havia o capital abstrato, que compreende a abstração realizada no quadro de um modo de produção específico, já que o que se tinha até então era um capital natural baseado na transmissão hereditária da habitação, das ferramentas, inclusive da clientela; sendo que sequer tinha sido engendrado o processo criador do trabalho abstrato, "simultaneamente geral e parcelar, indiferente ao trabalhador" (LEFEBVRE, 1972: 59). Trata-se, então, de um ciclo de acumulação primitiva, um período preparatório de "acumulação de riquezas, de técnicas, de mão-de-obra, de mercados, de lugares e territórios, de comunicações, etc" (LEFEBVRE, 1972: 60).

Tendo esse movimento de acumulação primitiva resultado na necessidade de expansão dos mercados, as cidades é que passaram a se relacionar umas com as outras: "as cidades comerciais se expandem e encetam relações entre si para se federarem ou se combaterem" (LEFEBVRE, 1972: 43), levando, enfim, à separação da produção industrial e do comércio. Temos, então, o nascimento das manufaturas, rompendo com o sistema corporativo da cidade medieval e demandando uma série de condições que passam a gerar transformações sociais, como a concentração demográfica e do capital. Ao passarem a assumir ramos industriais predominantes, surge, nas cidades, "com toda a clareza, uma divisão social do trabalho imposta pelo mercado e sua extensão" (LEFEBVRE, 1972: 60), a qual implica, de uma lado, uma ampla monetarização das relações e, de outro, o trabalho social, indiferente, alienado. Com isso, a produção agrícola deixa de ser a principal atividade produtiva e a riqueza deixa de ser sobretudo a imobiliária, completando-se, segundo essa interpretação do modelo clássico de transição para o capitalismo, a vitória da cidade sobre o campo. 
Nesta linha que compreende a História da modernização européia, quando o mercado passa a intermediar as relações sociais, surgem condições para uma revolução industrial e, com isso, uma nova mudança no caráter das relações cidade-campo. Este último (potencialmente) deixa de ser o lugar da produção, por excelência, para simplesmente assumir uma função particular e articulada na divisão social do trabalho a de viabilizar a produção especificamente capitalista de matérias-primas industriais e alimentos para os trabalhadores operários. A Revolução Industrial constitui, portanto, um período particularmente importante para o estudo da evolução da relação cidadecampo, a qual, aqui, nos interessa. A partir deste momento, começa um processo crescente de transformações radicais no conjunto geral das relações de produção. Se em toda a história da humanidade, anterior à referida Revolução, a agricultura sempre foi a principal atividade econômica e o campo representava o lugar em que se concentrava a grande maioria da população de produtores diretos, o surgimento de uma indústria capitalista moderna engendrou uma mudança demográfica nos países onde ela ocorreu inicialmente, invertendo a proporção entre a quantidade de população urbana e a quantidade de população rural, esta última esvaziada pelas levas migratórias de trabalhadores que partiram em direção às cidades.

Fazendo uma crítica contundente ao desmantelamento das relações sociais diretas provocado pela divisão do trabalho, o que, segundo os economistas burgueses clássicos, era a única forma de se aumentar a produção e gerar riqueza no interior das nações, Piotr Kropotkin escreve sua obra intitulada Campos, Fabricas e Talleres. Para o anarquista russo, o antigo artesão, que antes encontrava um prazer estético em suas obras, "foi substituído por um escravo humano unido a outro de ferro"; o trabalhador do campo, que outrora tinha estreita relação com a casa de seus antepassados, com a terra e também com a própria natureza, era anunciado como um anacronismo. Ele deveria ser substituído "por um servente acidental, tomado para o verão e despedido na chegada do outono; um desconhecido, que não voltará mais a ver o campo que regou uma vez em sua vida" (KROPOTKIN, 1978: 8). Os economistas e homens políticos teriam ido tão longe em seus "sonhos de divisão do trabalho" que proclamaram a necessidade de "dividir a humanidade inteira em oficinas nacionais, tendo cada uma delas sua especialidade particular". Uma vez proclamado que a riqueza das nações dependia do grau de especialização do trabalho, "resultava lógico especializar as nações, como se faz com os trabalhadores" (KROPOTKIN, 1978: 9). 
Considera-se, porém, que, "na medida em que o trabalho que se exige do indivíduo na produção moderna se faz mais monótono e cansativo", mais imperioso se faz o desejo de exercício das faculdades que tornam o ser humano "uma parte consciente de um grande-todo, um partícipe dos mais elevados prazeres da ciência e da arte, do trabalho livre e da concepção" (KROPOTKIN, 1978: 10). Também as nações, cada uma delas um agregado composto de "gostos e inclinações, de necessidades e recursos, de aptidões e faculdades", negam-se a ser especializadas. Sobre a relação cidade-campo, Kropotkin faz uma afirmação que está na base do pensamento anarcocomunista, corrente a partir da qual MARCOS (1996) identifica o autor russo: "a agricultura chama à vida a manufatura, e esta sustenta aquela; ambas são inseparáveis, e sua mútua combinação produz os maiores resultados" (KROPOTKIN, 1978: 10).

Para Kropotkin, enquanto a divisão temporária de funções segue como sendo uma maneira segura de se garantir o êxito de uma empresa, a divisão permanente encontra seus limites justamente na riqueza de aptidões e inclinações do indivíduo, assim como na variedade das mesmas dentro de cada agregado de seres humanos. Reclamava-se, então, os benefícios que poderiam ser proporcionados pela integração do trabalho:

Nós proclamamos a integração, e argumentamos que o ideal da sociedade, o estado para o qual marcha esta, é uma sociedade de trabalho integral, uma sociedade na qual cada indivíduo seja um produtor de trabalho manual e intelectual; na qual todo ser humano que não esteja impedido seja um trabalhador, e na qual todos trabalhem o mesmo no campo que na oficina industrial (...) (KROPOTKIN, 1978: 12).

Propõe-se, a partir da crítica à mais poderosa tendência de ordem social da época, que uma sociedade reorganizada teria de abolir as classes que se reproduzem mediante a divisão do trabalho, abandonando o erro de especializar as nações, devendo cada uma delas, assim como cada indivíduo, produzir a maior parte dos alimentos e das manufaturas de que necessita: “cada nação deve ser seu próprio agricultor e manufatureiro; cada indivíduo deve trabalhar no campo e em alguma arte industrial; cada um deve combinar o conhecimento científico com o prático" (KROPOTKIN, 1978: 12). A utopia de Kropotkin, apesar de parecer ingênua perante os constrangimentos sociais causados pela divisão do trabalho em um sistema-mundo, aponta para um elemento crítico que não pode ser perdido de vista ao se pensar o curso 
das relações cidade-campo na História. A idéia de que o campo deve simplesmente executar uma função na totalidade do processo produtivo é essencialmente apologética, já que nada faz além de justificar o processo capitalista de modernização.

O autor russo nos mostra, assim, a necessidade de identificar e pensar processos sociais que não se enquadrem no modelo teórico dos economistas burgueses. Devemos buscar compreender possibilidades na relação cidade-campo para além da pressuposta "vitória do campo sobre a cidade". Como veremos adiante, a compreensão do meio rural e de sua relação com a cidade em uma sociedade a exemplo da brasileira, cuja modernização resulta do processo de desenvolvimento desigual e combinado do capital, deve, portanto, considerar centralmente a possibilidade de o campo comportar usos que não se reduzem às determinações das relações de mercado e da agricultura industrializada, de modo que esse irredutível (ainda que subordinado ao movimento do capital na esfera da circulação de mercadorias) constitua a chave interpretativa da relação contemporânea entre campo e cidade.

\section{Contraponto entre as teorias da relação cidade-campo baseadas no modelo clássico e o desenvolvimento desigual do capitalismo no território brasileiro}

Muito da crítica à divisão do trabalho sugerida pelas obras (ainda que, em muitos sentidos, divergentes) de Marx e Kropotkin, entre outros autores, foi perdida ao longo do desenvolvimento dos ramos das ciências sociais, tais como a sociologia rural, tendo permanecido apenas a idéia de que o desenvolvimento das forças produtivas (preferencialmente incidindo na cidade e dela partindo) tende a generalizar as relações capitalistas no campo e engendrar uma modernização técnica, dissolvendo as estruturas arcaicas. Os estudos sociológicos, na origem da disciplina, marcados pela influência da filosofia positivista, passaram principalmente a constatar as diferenças entre o rural e o urbano, de modo a não mais do que justificar o processo histórico linear do capitalismo e, com ele, a relação funcional entre campo e cidade. Argumenta-se, a respeito do aparecimento dos estudos rurais na Europa, que:

(...) historiadores, geógrafos, folcloristas, sociólogos, no fim do séc. XIX tomam consciência da existência de um meio rural fundamentalmente diverso do urbano, pois, como resultado da revolução industrial que se processara, mais e mais se tornam diversos campo e cidade, com o predomínio da indústria sobre a agricultura, da 
cidade sobre o campo, da invasão do campo pela máquina (QUEIROZ, 1979: 161).

A sociologia rural surge, portanto, como conhecimento instrumental voltado para a superação do suposto atraso no campo. Segundo MARTINS (1986), com a urbanização da sociedade, emerge uma crise marcada por um conjunto de transformações sociais relacionadas à intensa migração do campo para a cidade, com o conseqüente esvaziamento do campo. $\mathrm{O}$ campesinato, que compunha a grande maioria da população de países que, como o Brasil, vieram a conhecer um processo de modernização considerado, de um ponto de vista evolucionista, "tardio", passava a ser enxergado como o atraso, o arcaico, na medida em que representava um empecilho para o "pleno desenvolvimento das forças produtivas" nacionais, com sua "economia de subsistência".

Já o ideal de "modernização do campo" advinha das transformações ocorridas nas técnicas agrícolas visando o aumento da produtividade que vinham sendo operadas desde a associação da criação de animais à agricultura, e culminaram com a introdução dos adubos minerais ao final do século XIX (a chamada Revolução Agrícola). Trata-se de um processo sem o qual não teria sido possível o grande crescimento metropolitano das cidades européias industrializadas.

O desenvolvimento dos mercados internos nacionais e das relações de trabalho no campo nos países de "desenvolvimento tardio" sugeria uma tendência de desaparecimento da economia "de base natural", notada inicialmente por autores como LÊNIN (1982) e KAUTSKY (1968), e refutada, porém, por CHAYANOV (1986), segundo o qual a especificidade da forma da economia doméstica representava um caminho à parte no curso da modernização capitalista.

A partir de então, passou-se a advogar que a função do campo seria univocamente a produção de alimentos e matérias-primas, em quantidade a maior possível e a preços mantidos nos mais baixos patamares, de modo suficiente para abastecer o crescente contingente de operários nas indústrias e de trabalhadores urbanos em geral, bem como garantir o suprimento de capital circulante nestas indústrias. É com essa finalidade que, em meados do século XX, a introdução e o emprego massivo de tecnologia científica e industrial na agricultura aproximou-a da própria indústria (a chamada Revolução Verde), surgindo, no seio desse processo, uma agricultura voltada à produção capitalista de mercadorias e atrelada à economia mundial, passando a atender 
diretamente às demandas das metrópoles que não paravam de crescer e concentrar funções.

Enfim, originando-se no momento em que os intelectuais começam a dar conta destas transformações (as migrações rural-urbano, de um lado, e a tecnificação do trabalho no campo, de outro), o pensamento sociológico voltado à compreensão do mundo rural expressa a influência do conservadorismo e do cientificismo, ou seja, busca indiretamente legitimar uma ordem vigente, encobrindo os conflitos que mostravam profundas contradições dessa mesma “ordem” (MARTINS, 1986). Conseqüentemente, geram-se teorias sociológicas baseadas em pares de idéias constitutivas opostas, e não contraditórias, propostas como "fundamento de diagnóstico das descontinuidades da vida social, de modo que em cada termo da dicotomia não haja ambigüidade" (MARQUES, 2002: 101). A partir da crítica ao uso de dicotomias no surgimento da sociologia rural, situando-a como conhecimento instrumental criado diante de uma crise do próprio capitalismo, afirma-se, porém:

Esta colocação do problema traz implícita a afirmação de que nem sempre teria havido heterogeneidade marcada entre campo e cidade, ou melhor, que as relações entre ambos não teriam sido sempre as mesmas (QUEIROZ, 1979: 161).

Ou seja, neste texto que é também uma revisão de sua própria obra, QUEIROZ (1979) se coloca contra toda uma corrente originária da sociologia que propõe classificações dicotômicas e estanques para a interpretação das dinâmicas sociais, partindo, assim, para o estudo das inter-relações entre cidade e campo. Para isso, com base na obra de Robert Redfield, QUEIROZ (1979) sugere três configurações maiores de estrutura e organização social, de modo a compreender, a partir dessas sociedades globais, a relação cidade-campo. Teria primordialmente havido uma sociedade tribal, com fraca divisão do trabalho e em que inexistia a concentração urbana; outra sociedade agrária, na qual a cidade surgiu e passou a organizar e dominar o meio rural, não podendo, porém, ultrapassar demograficamente os limites impostos pelo abastecimento proveniente do campo, já que a cidade era essencialmente um centro políticoadministrativo; e, finalmente, a sociedade urbana, em que, "devido ao desenvolvimento cada vez maior da tecnologia, a cidade se libertou do meio rural no que toca à produção em geral", reorganizando o trabalho agrário e "impondo ao meio rural seu gênero de vida e sua estratificação social de base econômica" (QUEIROZ, 1979: 161). O que, 
enfim, teria permitido à cidade um crescimento demográfico fundamentalmente dependente do desenvolvimento tecnológico, e não da quantidade de trabalhadores no campo. Portanto, segundo esta teoria, encontram-se imbricados o grau de divisão do trabalho nas sociedades, sua densidade demográfica, que expressa no território o continuum entre o meio urbano e o meio rural, e a natureza das relações sociais (se afetivas ou, ao contrário, indiretas e indiferentes); dados, estes, que, de fato, tornam progressivamente distintos, porém, inter-relacionados, o campo e a cidade. Quanto a esta inter-relação, propõe-se analisar suas transformações ao passo da evolução das sociedades globais:

Dentro da tipologia acima para as sociedades globais, o equilíbrio entre campo e cidade será diverso conforme o tipo. (...) Nas sociedades agrárias, cidade e campo coexistem, mas o campo domina a cidade, embora esta o organize e seja seu centro administrativo; a dominação é demográfica e econômica. Nas sociedades urbanas, a coexistência também se verifica entre campo e cidade, porém a cidade domina o campo, que passa para um plano secundário, demográfica e economicamente (QUEIROZ, 1979: 162).

É importante frisar a idéia de que, para esta corrente do pensamento sociológico, os três tipos de sociedades identificados "podem ser concomitantes no tempo e no espaço numa sociedade como a brasileira" (QUEIROZ, 1979: 162). Portanto, uma mesma sociedade global pode "reunir em arranjos variados ou os três tipos sociais, ou dois deles, variando o grau de dominação de cada um, e formando tais sociedades complexos sincréticos" (QUEIROZ, 1979: 163), sendo necessário encontrar, em cada sociedade global, o tipo dominante. Segundo os pressupostos desta teoria, baseada no princípio do continuum rural-urbano, o meio rural "não pode nunca ser estudado em si mesmo, mas deve ser encarado como parte de um conjunto social mais amplo, do qual faz parte juntamente com a cidade" (QUEIROZ, 1979: 163).

Questionando-se sobre o avanço do processo de urbanização e da "industrialização" da agricultura, os estudos que defendem a idéia de continuum ruralurbano afirmam a tendência a uma maior integração entre cidade e campo, com a modernização deste e a conseqüente destruição de formas arcaicas. A exemplo do trabalho de Henri Mendras, admite-se uma "diferença de intensidade, e não contraste entre esses dois espaçoo" (MARQUES, 2002: 100). Todavia, a idéia de continuum também se apóia sobre uma concepção dual: para esta teoria, o rural e o urbano não 
seriam outra coisa além de dois pontos extremos entre os quais admite-se uma gradação. Este ponto de vista evolucionista também pressupõe que a generalização das relações de mercado viria a urbanizar o campo, arrefecendo qualquer possibilidade de se perceber contradição na relação entre processos sociais urbanos e do meio rural.

Em suma, segundo MARQUES (2002), as definições sociológicas sobre o campo e a cidade podem ser relacionadas a estas duas grandes abordagens: a dicotômica e a do continuum.

Na primeira, o campo é pensado como meio social distinto, que se opõe à cidade. Ou seja, a ênfase recai sobre as diferenças existentes [classificações] entre estes espaços. Na segunda, defende-se que o avanço do processo de urbanização é responsável por mudanças significativas na sociedade em geral, atingindo também o espaço rural e aproximando-o da realidade urbana (MARQUES, 2002: 100).

Mas, para melhor compreendermos o processo histórico contraditório que opõe o campo e a cidade, bem como o modo como ele se acirra com o desenvolvimento das forças produtivas do capitalismo, vejamos a proposta de periodização do tempo sociohistórico segundo LEFEBVRE (1971). O autor francês sugere uma forma de compreensão das sociedades com base justamente nos conflitos articuladores do processo histórico, no agravamento da divisão do trabalho e no movimento de criação e recriação das relações de produção, evitando o vício de demarcar o desenvolvimento temporal dos acontecimentos de maneira estanque, assim como o erro de interpretar quaisquer fenômenos a partir de periodizações de caráter evolucionista e/ou apriorístico. Teríamos, a princípio, as seguintes "eras": uma era campesina, com o predomínio do campo ou da produção agrícola, com suas relações específicas de produção e seus problemas; outra era industrial, com o predomínio da empresa industrial e sua racionalidade, opondo a propriedade privada à socialização do processo de produção, situando o proletariado contra a burguesia; finalmente, teríamos uma era urbana e sua problemática específica, como, por exemplo, os conflitos entre integração e segregação, entre as formas de centralidade (entre a centralidade como forma versus seus conteúdos), entre o urbano e o Estado.

O importante desta periodização é notar que, assim como na proposta de Maria Isaura Pereira de Queiroz, um periodo contorna o outro, seus problemas se superpõem, se exasperam. A descontinuidade entre eles é apenas relativa; o início de cada período deva ser entendido não como simples emenda, mas como uma nova página do texto 
social. O urbano anuncia-se, declara-se e significa algo de novo. Mas esta nova problemática urbana inclui e agrava os conflitos e contradições da era industrial que, por sua vez, contorna o período campesino, cada vez mais distante no tempo e no espaço, mas não totalmente resolvido (LEFEBVRE, 1971). Portanto, no sentido de apontar a diferença dessa teoria em relação à formulação das sociedades globais proposta no interior da teoria do continuum, poderíamos inferir que, para Lefebvre, as contradições hegemônicas no interior das sociedades (que, enfim, determinam o curso geral do processo histórico dessas mesmas sociedades) não eliminam problemáticas não resolvidas de períodos anteriores. Englobam-nas, inclusive agravando suas contradições, uma vez que elas passam a ser mediação nos conflitos de problemáticas hegemônicas. Estas problemáticas não resolvidas em outros tempos históricos não formam uma gradação em relação à problemática hegemônica atual, mas são uma outra coisa, possuem uma outra substância; ao mesmo tempo, são incorporadas e reproduzidas sob novas bases econômicas e sociais e tornam mais complexas as novas tensões.

Assim, podemos conceber que o campo e a cidade, ao contrário do que sugerem as análises baseadas no desenvolvimento linear do capital e da modernização no campo, entram como condição essencial para a composição de uma totalidade que combina aquilo o que o próprio processo histórico separou no passado com a divisão do trabalho. Para OLIVEIRA (1991), mesmo com a crescente e aparentemente unívoca modernização da agricultura no Brasil, o campo ainda tem sido um dos lugares privilegiados para se entender o desenvolvimento desigual do modo capitalista de produção, pois é fundamentalmente lá que encontramos as condições que levam à reprodução das relações de produção não-capitalistas:

Se, de um lado, o capitalismo avançou em termos gerais por todo território brasileiro, estabelecendo relações de produção especificamente capitalistas, promovendo a expropriação total do trabalhador brasileiro no campo, colocando-o nu, ou seja, desprovido de todos os meios de produção; de outro, as relações de produção nãocapitalistas, como o trabalho familiar praticado pelo pequeno lavrador camponês, também avançaram mais (OLIVEIRA, 1991: 11).

Segundo esta linha de interpretação das relações de produção no modo de produção capitalista, é no processo de trabalho que se define a essência da economia em uma unidade de produção camponesa. Baseado no trabalho familiar e, portanto, na 
indistinção entre a força-de-trabalho e a pessoa mesma do trabalhador, obtém-se gêneros agrícolas que, a despeito do seu valor de uso, também incorporam um valor de troca, constituindo-se como mercadorias. A necessidade de vender estas mercadorias, bem como a necessidade de comprar outras, as quais o próprio camponês não pode produzir, encerram, por sua vez, a integração e subordinação da economia doméstica (portanto, de base não-capitalista) ao processo do capital. Isso se traduz enquanto monopólio do capital comercial sobre a circulação das mercadorias produzidas no interior da unidade de produção doméstica. Por isso, entende-se:

(...) o desenvolvimento do modo capitalista de produção na sua fase monopolista como um processo contraditório de reprodução ampliada do capital, ou seja, o modo capitalista de produção não está circunscrito tão somente à produção, mas também à circulação de mercadorias. Isso decorre do fato de que ele não é na essência um modo de produção de mercadorias em seu sentido restrito, mas sim um modo de produção de mais-valia (OLIVEIRA, 1991: 48).

Mas, mesmo diante da sujeição ao capital na esfera da circulação de mercadorias, o processo de trabalho no qual a produção de gêneros agrícolas se baseia não compreende fundamentalmente $o$ assalariamento, relação de trabalho especificamente capitalista. Tampouco o camponês é um pequeno capitalista cujo trabalho é exclusivamente regulado pela demanda do mercado, porque a lógica da produção doméstica não compreende a circulação de dinheiro como capital (a valorização do valor como um fim em si mesmo), mas como meio de satisfazer as necessidades familiares (na teoria marxiana, a circulação simples de mercadoria, vender para comprar, isto servindo de meio a um fim último situado à margem da circulação).

O camponês integra-se de maneira subordinada à sociedade capitalista porque necessita vender seu produto para adquirir outros necessários à sua própria sobrevivência, além de ter que investir na especialização da produção agrícola devido às demandas do mercado monopolista. É no processo de circulação do capital, pois, que a economia de base doméstica se vê invadida e transformada pelas determinações do modo de produção em sua fase de reprodução ampliada. Ou seja, o processo do capital aproveita-se de qualquer forma de relação de produção, e não somente do trabalho assalariado, para apropriar-se de maneira privada do valor gerado no processo de trabalho. Eis como, com base na teoria da acumulação primitiva do capital, se distingue 
a sua produção de sua reprodução ampliada: “(...) é muito importante discernir entre produção do capital e reprodução capitalista do capital. A produção do capital nunca é capitalista, nunca é produto de relações capitalistas de produção, baseada pois no capital e no trabalho assalariado" (MARTINS, 1981: 170).

O capital é caracterizado por apropriar-se da riqueza adicional gerada em relação aos custos da reprodução da força de trabalho, ou seja, da mais-valia. Mas, uma vez constituído o capitalismo, este mesmo capital teve e tem tido condições de se apropriar até mesmo do valor gerado por trabalhadores que não foram separados dos seus meios de produção, principalmente a terra. Por isso, além da subordinação camponesa ao mercado, é importante ainda destacar a sujeição da renda da terra ao capital (MARTINS, 1980). O principal instrumento de produção do camponês é a terra; um instrumento que não contém valor, pois não é produto do trabalho, mas que tem potencial para que nele se produza. Por isso, o preço da terra, ou seja, a conversão da renda fundiária ou territorial em equivalente de capital, é uma irracionalidade: ela é uma dedução do capital disponível para o investimento na produção. Porém, a terra constitui condição geral da produção capitalista, especialmente na agricultura, criando uma situação em que o camponês passa a se defrontar também com a conversão da própria terra em mercadoria. Tanto a relação com o mercado quanto a relação com o proprietário fundiário constituem os principais focos de tensão quando se toma como referência central a base material da economia agrária, constatação sobre a qual MARTINS (2003) faz o seguinte comentário:

Seu conflito [do camponês] com o capital pode se abrir em duas frentes. Ou luta pela terra quando se defronta com o especulador imobiliário que há no capitalista do capitalismo rentista (...), ou luta pela elevação dos preços ou pela redução dos juros, um característico conflito de interesses, próprio da sociedade capitalista e não estranho a ela, que não representa, de fato, nenhuma possibilidade de superação do capitalismo. O mais importante desses conflitos, do ponto de vista histórico, é a luta pela terra (MARTINS, 2003: 88).

Luta, essa, que, ainda segundo MARTINS (2003), não propõe a superação do capitalismo, mas sua humanização. Anuncia a possibilidade de sujeição da propriedade à sua função social, questionando, pois, a propriedade privada como fundamento da propriedade capitalista. Sugerem que a renda gerada no processo de trabalho sobre a terra seja empregada na continuidade da vida e no desenvolvimento social e não em um 
processo que se alimenta da exploração do trabalho, da apropriação privada do maisvalor gerado pelo trabalho social, como são os casos da agricultura capitalista, da agroindústria, dos capitais comercial e financeiro, estes, atendendo diretamente às demandas das metrópoles ou nelas sediados e organizados.

\section{A tentativa de revalorização do ("novo") rural no debate brasileiro e os caminhos abertos pela compreensão dialética da relação cidade-campo no Brasil}

Antes, enfim, de realizar nossos apontamentos sobre as implicações da teoria do desenvolvimento desigual do capital na relação cidade-campo, faremos uma breve exposição sobre como sociólogos, economistas e geógrafos vêm pensando este

problema diante daquilo o que, de maneira ainda muito genérica, podemos chamar "o caso brasileiro". Isso quer dizer: como o esforço de interpretação de uma realidade particular empreendido pelas ciências sociais brasileiras veio refletindo as grandes correntes teóricas da sociologia rural e quais desafios se colocam em função da potência do instrumental de análise disponível em face da conjuntura histórica concreta das relações cidade-campo no Brasil.

$\mathrm{Na}$ tentativa de solucionar estas questões, atualmente, as funções e os conteúdos dos espaços rurais (portanto, sua relação com a cidade e, especialmente, seus mercados urbanos) têm sido estudados principalmente a partir de uma perspectiva instrumentalista (identificada e criticada por MARQUES, 2000), representada pelos autores que apregoam as "novas estratégias de desenvolvimento rural". No entanto, esse mesmo conjunto de autores vem pensando um "velho" papel (subordinado) para o campo em sua relação com a cidade, pressuposto que está por trás do conceito de agricultura familiar (ABRAMOVAY, 1992) e da idéia de que o meio rural teria deixado de ser predominantemente agrícola, restando apenas a alguns agricultores mais "dinâmicos" e "eficientes" um lugar no "novo rural” - denominação, esta, de GRAZIANO DA SILVA (1996), criada para exprimir o crescimento do setor de serviços no meio rural, este último cada vez mais urbanizado, portanto.

$\mathrm{Na}$ análise da relação cidade-campo, leva-se em consideração um conjunto de particularidades que tornam o meio rural uma função necessária ao desenvolvimento dos países, principalmente (a exemplo dos países centrais do sistema mundial capitalista) na sua política de ordenamento territorial (como é o caso das áreas de 
Cinturão Verde instituídas ao redor de cidades como Londres), além, evidentemente, desse meio rural ser estratégico para as políticas de Estado baseadas no conceito de segurança alimentar. Para estes autores, não cabe falar em desaparecimento do rural, mas, sim, em uma relação de funcionalidade deste para com a demanda dos mercados urbanos, considerando-se suas características sociais e também paisagísticas como dados essenciais para o exercício dessa funcionalidade.

No sentido de gerar instrumentos estatísticos para esta linha de argumentação, VEIGA (2002) faz uma crítica à classificação de população rural e de população urbana adotada pelo IBGE, a qual é obtida por este instituto de pesquisa com base na contagem dos habitantes residentes nos perímetros urbano e rural de cada um dos municípios brasileiros. Porém, alguns núcleos urbanos no interior desses municípios seriam pequenos demais para que sua população, residente em aglomerados que não exercem funções importantes, fosse considerada urbana, o que introduziria uma distorção nas interpretações feitas com base em tais dados. José Eli da Veiga propõe, então, uma outra classificação, baseada, desta vez, na densidade demográfica e no grau de artificialização dos ecossistemas, os possíveis indicadores do grau de urbanização dos territórios.

O ponto de partida desta atualmente influente corrente teórica é o de que, ao contrário da completa polarização social no campo, prevista por autores de orientação leninista, o rural tornou-se novamente uma potência econômica por suas qualidades intrínsecas, comportando múltiplas atividades e funções. Contra a dicotomia na concepção de urbano e de rural, ABRAMOVAY (2000) vê um continuum entre espaços essencialmente rurais, relativamente rurais e essencialmente urbanos. Este autor também ressalta que, na literatura internacional, define-se ruralidade a partir de três aspectos: a importância das áreas não densamente povoadas, a relação com a natureza e a dependência do sistema urbano, donde se concebe a idéia de que o rural não seja uma categoria de natureza setorial, e sim, territorial (ABRAMOVAY, 1999), ponto em consonância dessa obra com os pressupostos do rurbano de GRAZIANO DA SILVA (1999). É enfatizada, assim, a noção de territorialidade para exprimir o meio rural, destacando-se a complementaridade e articulação desses dois espaços, sem que isso implique necessariamente a anulação de um deles. Mas o que estes autores entendem por território, se não a mera dimensão espacial do conceito de vantagens comparativas? 
São proposições que buscam defender a viabilidade econômica do espaço rural em detrimento da sociabilidade camponesa cuja reprodução, entendemos nós, se coloca como vetor fundamental da produção e das lutas sociais a partir deste espaço: "sua análise, de caráter instrumental, restringe-se a uma perspectiva econômica e não problematiza os aspectos sociais envolvidos nas mudanças verificadas na relação cidade-campo" (MARQUES, 2002: 99). Entendemos também que a fração rural do território (ou melhor, o campo) não representa somente um conjunto de vantagens econômicas para o empreendimento rural (mesmo o não-agrícola), mas uma teia de relações sociais que giram em torno das relações de trabalho e da apropriação da terra, o que envolve tanto a superestrutura jurídica do Estado quanto o direito costumeiro, as subjetividades criadas em torno do processo de trabalho doméstico, as quais têm a hereditariedade da propriedade da terra como um de seus mais importantes elementos.

Do ponto de vista do desenvolvimento territorial rural, posição defendida por ABRAMOVAY (1999), a partir da idéia de agricultura familiar, e por GRAZIANO (1999), com o conceito de multifuncionalidade, quando o campo se associa à cidade (ou seja, passa a produzir mais eficientemente, para suprir uma necessidade imposta a partir dos centros urbanos), ele está crescendo, se desenvolvendo. A cidade também se beneficia, pois vê no campo (em desenvolvimento) evidências do meio rural como um valor, expresso, por exemplo, por sua possível função na preservação ambiental, na criação de "sociedades sustentáveis". Mas o que temos, do ponto de vista das contradições sociais, é exatamente o contrário da utopia de integração do trabalho defendida por KROPOTKIN (1978). Temos, sim, um aprofundamento da divisão do trabalho no sentido de complementaridade forçada entre desiguais.

Observemos o problema de uma perspectiva menos otimista, constatando a condição segundo a qual se organizam espacialmente as forças produtivas no território brasileiro, para então pensar a relação cidade-campo. SANTOS (1994) indica que, para entender a lógica espacial das sociedades contemporâneas, há que se levar em conta o papel da ciência, da tecnologia e da informação. Tanto no campo como na cidade, os acréscimos técnicos ao solo são condições exigidas para a instalação de atividades mais modernas. Por isso, o campo e a cidade responderiam de maneiras diferentes às exigências modernizadoras: o campo, devido às suas propriedades intrínsecas, seria mais facilmente adaptável, ao contrário da cidade, cuja rigidez material e funcional dificultaria a introdução de novas racionalidades (SANTOS, 1994). Assim, o campo 
responderia mais prontamente aos avanços do capital, sendo que as zonas rurais nos países de Terceiro Mundo, hoje, resultam, segundo sua função diante das demandas geradas a partir dos centros de decisão localizados nas metrópoles, em nada além de um aperfeiçoamento daquilo o que já havia sido forjado na Revolução Verde: um membro funcional da produção econômica a serviço de uma racionalidade única.

É verdade que a corrente teórica que apregoa o desenvolvimento rural parte de uma perspectiva crítica em relação ao modelo modernista de sociedade, o qual previa para o campo um desenvolvimento baseado nos preceitos da dita Revolução. Não aceita a idéia de que teria havido um processo de urbanização de toda a sociedade, colocandose contra o pressuposto de que o futuro da produção agrícola no campo estaria todo ele nas mãos de grandes empresários capitalistas que exploram o trabalho do proletariado rural. Por isso, sua formulação de agricultura familiar. Esta se colocaria contra o modelo da Revolução Verde, desde que fomentada, de alguma maneira, pelo Estado. Mas com essa associação entre desiguais implícita (e justificada) nesta visão das relações campocidade, toda a vocação do campo para lugar criador de obras, de valores de uso, vai sendo corroída, dissolvida, recriada de maneira a homogeneizar sua paisagem e os processos que o animam, ou seja, suas relações de produção e toda sua vida comunitária, ainda que isso tenha sido realizado de maneira sempre incompleta. Neste sentido mora nossa crítica a esta corrente de pensamento que vem influenciando os recentes estudos rurais e, principalmente, as políticas públicas voltadas ao desenvolvimento rural. Ela somente enxerga o empreendimento agrícola familiar, supostamente conduzido de maneira exclusiva pela lógica de mercado, e não mais segundo a lógica tradicional das sociedades assim chamadas parciais; não leva em consideração a importância da teia de relações que se desenrola e condiciona a permanência da família camponesa na terra, ou seja, sua reprodução. Enfim, também entende que a relação campo-cidade foi reduzida a uma simples cooperação funcional.

Contra a totalidade dessa linha argumentativa que negligencia a complexidade horizontal no desenvolvimento mundial do capitalismo (ou seja, seu desenvolvimento desigual), deduzindo disso a anulação das contradições nas relações entre campo e cidade (devido a uma suposta generalização do trabalho indiferente, resultado da primazia da cidade moderna sobre o campo), examinemos alguns autores que nos lançam desafios e nos sugerem outros instrumentos para analisar a relação cidadecampo no Brasil. 
$\mathrm{Na}$ busca da superação do hiato entre as sociologias rural e urbana, QUEIROZ (1978) já tinha proposto o caminho da dialética para a análise dos fenômenos concretos que compõem a realidade empírica. Na base desta proposição está a concepção de que os fenômenos da sociedade e do universo “(...) não são mais do que aspectos da matéria em movimento histórico, que se condicionam reciprocamente segundo leis necessárias, expressas na dialética - e as mesmas leis regem a aquisição do conhecimento" (QUEIROZ, 1978: 30). A ligação dos fenômenos do universo não pode ser desmembrada tranqüilamente:

(...) pelo contrário, objetos e fenômenos estão organicamente ligados (como organicamente ligados estão matéria e pensamento), dependem uns dos outros e se condicionam reciprocamente. Nenhum fenômeno do universo pode ser compreendido isoladamente, destacando do meio em que surgiu e ao qual se liga, numa posição que lhe é específica e que também se transforma (QUEIROZ, 1978: 31).

Os instrumentos dialéticos de análise do concreto sugerem que "o movimento inerente à matéria e a todos os fenômenos decorre da contradição" (QUEIROZ, 1978: 31). É por esta razão que, em seu estudo, QUEIROZ (1978) busca verificar, em diferentes momentos históricos latino-americanos, as maneiras também diversas de se inter-relacionarem o rural e o urbano, de modo a não se anularem mutuamente. Para efetuar este esforço, ela lança mão das dialéticas múltiplas propostas por Georges Gurvitch. Embora seja possível e pertinente a ressalva de que esta forma de discernir categorias no movimento essencial do real possa levar-nos de volta ao vício da mera classificação dos fenômenos, as conclusões apontadas abrem caminhos para que possamos, hoje, negar o pensamento unívoco a respeito das relações campo-cidade.

Assim, primeiramente temos uma comparação das relações cidade-campo estabelecidas nos casos das Américas Hispânica e Portuguesa, apontando suas divergências. No primeiro caso, a colonização "foi uma empresa guerreira de dominação de grupos sociais estratificados que já conheciam a distinção entre o rural e o urbano" (QUEIROZ, 1978: 36). Para o colonizador espanhol, era estratégica a existência prévia de cidades e, portanto, da relação cidade-campo já estabelecida. Preservou-se a estrutura que "concentrava nas cidades a burocracia indispensável para a cobrança de impostos e para o controle das diversas regiões", nas quais "o trabalho das minas e o trabalho rural persistiam" (QUEIROZ, 1978: 36). Neste caso, as relações 
entre cidade e campo "tomaram o aspecto de uma dualidade em oposição, numa dialética de polarização" (QUEIROZ, 1978: 37).

De maneira distinta, na América Portuguesa “(...) não se tratava de conquistar, e sim povoar um vasto território dotado de população relativamente pouco numerosa, dispersa, estruturada em grupos de pequeno porte, de tecnologia pobre, nômades, e portanto desconhecendo cidades (...)" (QUEIROZ, 1978: 37). Estas, reduzidas ao mínimo necessário para o projeto colonial português, eram freqüentemente vazias (a não ser em tempos de festa religiosa). Nem mesmo se buscou disciplinar as relações étnicas, de modo que eventualmente eram considerados "brancos" os indivíduos miscigenados para, desta forma, aumentar a população dominante, surgindo, então, a condição ambígua do liberto (nem escravo, nem homem livre). Assim, não se desenvolveu "na colônia luso-brasileira uma dualidade marcante campo-cidade, concentrando-se a vida sócio-econômica nas propriedades grandes, médias e pequenas" (QUEIROZ, 1978: 39). Trata-se, portanto, da dialética da implicação mútua, em que os elementos, à primeira vista heterogêneos, seguem a mesma direção e se contém reciprocamente (sem perder sua identidade específica).

Com a chegada da Família Real no Rio de Janeiro (onde passou a concentrar-se uma camada social diferente e dominante, a qual nada tinha a ver com o campo) e, posteriormente, com a independência do país, cresce a importância das capitais provinciais e da capital federal. O capital gerado no campo era usado para embelezar as cidades, mas não para levá-las a produzir; portanto, as cidades onde se centralizava o poder político se desenvolviam de modo dependente do meio rural:

Uma nova dialética pouco a pouco se substituiu à dialética da imanência mútua, porém não é uma dialética de contrários entre cidade e campo; por muito tempo, reinaria a dialética da complementaridade, pois cada um se afirmava em função do outro, não podendo ser compreendido isoladamente, nem ser também reduzido ao outro, e concorrendo um ativamente para a vigência do outro (QUEIROZ, 1978: 40-1)

Em seguida, QUEIROZ (1978) analisa o desenvolvimento do processo histórico brasileiro a partir da comparação entre o fato agrário e o fato industrial. De modo contrário ao pressuposto de que a industrialização é o fundamental motor da urbanização, somos lembrados de que a urbanização, dependendo da conjuntura histórica, é um processo anterior e independente da industrialização. Atribui-se esta 
negligência ao fato de os cientistas sociais terem abandonado o estudo das “(...) relações que [as cidades] mantêm com o meio rural circundante, por um lado, e por outro lado com a sociedade global na qual estão implantadas" (QUEIROZ, 1978: 43). A única preocupação era, como já vimos anteriormente, a de compreender a dominação da cidade sobre o campo, de modo a se cair em uma antinomia sem retorno. Temos, porém, que o próprio desenvolvimento industrial era dependente do meio rural, como é possível verificar no caso da urbanização de São Paulo, em que a agricultura de exportação atuou na formação do capital, na concentração de mão-de-obra e na formação de um mercado para os bens de consumo, além do desenvolvimento da administração pública (QUEIROZ, 1978:46). Assim, quanto à indústria que surgia em São Paulo, “(...) a agricultura de exportação no Brasil agiu como um elemento que a fomentou; e quanto à urbanização, o papel incrementador da agricultura foi decisivo" (QUEIROZ, 1978: 47). Portanto, a relação cidade-campo não era de mera oposição, mas de ambigüidade, de ambivalência (dada quando cada termo não tem apenas um sentido, mas vários, os quais podem convergir em determinado momento). Paulatinamente, porém, a “industrialização industrializante” da década de 1950 em São Paulo, veio substituir esta ambigüidade por uma nova dialética da complementaridade entre cidade e campo, dada quando a "região industrializada age (...) como centro integrador que vai progressivamente articulando as outras regiões do país" (QUEIROZ, 1978:48). Portanto, uma relação não muito diferente daquilo o que vimos até aqui chamando de caminho unívoco das relações cidade-campo (lembrando que, para esta autora, a complementaridade entre os termos da questão não se dá sem que haja a irredutibilidade dos termos entre si).

Contudo, esta é uma abordagem que nos abre caminhos e nos leva à reflexão acerca do momento atual. Diversos trabalhos na mesma linha vêm nos inquietando a respeito de como compreender a relação campo-cidade sem cair no funcionalismo economicista. LENCIONI (1985), por exemplo, nos mostra como o processo de capitalização no campo levou à urbanização do aglomerado urbano no município de Jardinópolis e, com isso, à mudança nas relações de trabalho no campo. SUZUKI (1996) mostra como a transformação do povoado de Rondonópolis em cidade ocorre juntamente à passagem da frente pioneira sobre a frente de expansão, ou seja, conforme se dá a expansão da propriedade privada da terra nesta localidade. No entanto, ao analisar essa passagem, SUZUKI (1996) supera a idéia de que haveria duas estruturas 
estanques de temporalidade única, de características puras, avançando uma sobre a outra no espaço. Contra esta teoria, o autor leva em consideração a análise das transformações e a presença de resíduos, uma mistura de tempos históricos em um só tempo cronológico, mas com a predominância de características de uma ordem dominante.

SUZUKI (1996) considera, então, o processo de urbanização como um movimento não contínuo, homogêneo, linear. A análise da urbanização por meio apenas do crescimento demográfico e das mudanças no uso do solo não seria suficiente para a compreensão do processo social que ali se instalou com a chegada da frente pioneira. Ao invés de lançar mão das teorias demográficas para explicar a urbanização, o eixo deste trabalho foi o da expansão da propriedade privada da terra, que não só expropria o posseiro, mas altera o ritmo daquele povoado (que se transforma em cidade) e do meio rural circundante, cada vez mais atrelado à economia de mercado, alterando-se, assim, a própria relação campo-cidade. Todavia, para não cair no estruturalismo, na idéia de dois momentos distintos, constituídos cada qual de características particulares e puras (para não incorrer em uma classificação, enfim), ele propõe a idéia de sobreposição de temporalidades diferenciadas no curso do processo de transformação do povoado em cidade (SUZUKI, 1996).

Assim, temos que o desenvolvimento linear do capital, bem como sua implicação supostamente unívoca sobre a relação cidade-campo, não condiz com a realidade complexa apreendida ainda nos dias de hoje nas relações de produção rurais em países de industrialização tardia como o Brasil, já que o campesinato, com seu processo de trabalho e suas representações particulares, mantém significativa presença não só na produção de mercadorias, mas também nas lutas políticas (conforme apontam os estudos de Theodor Shanin e, no Brasil, de José de Souza Martins e Ariovaldo Umbelino de Oliveira), reproduzindo-se numa relação contraditória com as determinações do modo de produção.

Para não incorrermos na apologia da generalização absoluta da complementaridade forçada, da separação radical entre o trabalho e o trabalhador, é preciso que o método e seus instrumentos dêem conta de explicar a lógica contraditória da recriação de temporalidades que representam a diferença e a oposição na relação entre cidade e campo. Eis o motivo por conta do qual entendemos que a teoria do desenvolvimento desigual e combinado do capital pode abrir novas frentes de questionamento acerca das relações campo-cidade no caso brasileiro: 
A sociedade moderna é constituída por uma multiplicidade de relações datadas. Cada segmento social ou aspecto desta realidade possui sua própria temporalidade e seu próprio ritmo de movimento. Esta pluralidade dos tempos históricos implica o desenvolvimento desigual e combinado da sociedade. (...) Mesmo sob uma tendência homogeneizadora ocorre a recriação da diferença numa perspectiva de complementação e antagonismo. Tal fato explicaria a existência de diferentes modos de vida no seio da sociedade capitalista (MARQUES, 1994: 9).

Destes apontamentos extraímos que o campo novamente entra em relação de tensão com a cidade na medida em que o capital, cuja reprodução é organizada a partir dos centros de decisão sediados nas metrópoles, aproveita o trabalho não capitalista e o modo de ser camponês para acumular aquilo o que ele mesmo não pode produzir. Apesar de progressivamente integrados técnica e economicamente, campo e cidade reproduzem tensões que não estão em pleno acordo com seus processos aparentemente inerentes. O campo não se reduz a uma função, mas, antes, aparece como necessidade insubstituível no interior da reprodução ampliada do capital. No sentido contrário, as lutas no campo brasileiro contemporâneo pressionam os centros de decisão e questionam o modelo de desenvolvimento da sociedade brasileira ali sediado e dali irradiado. Temos, enfim, colocadas as possibilidades de se utilizar o instrumental dialético para analisar a realidade empírica das relações campo-cidade na contemporaneidade, metodologia que potencialmente traz novas perspectivas para o problema, as quais já tinham sido apontadas no trecho a seguir, com o qual finalizamos em aberto:

Campo e cidade, cidade e campo, formam uma união contraditória. Uma unidade onde a diferença entre os setores da atividade econômica (...) vai ser soldada pela presença na cidade do trabalhador bóia-fria do campo. As greves dos trabalhadores do campo são feitas na cidade. Ao mesmo tempo, podemos verificar que a industrialização dos produtos agrícolas pode ser feita no campo com os trabalhadores das cidades. Aí reside um ponto importante nas contradições do desenvolvimento do capitalismo, tudo indicando que ele mesmo está soldando a união contraditória daquilo o que ele separou (...). Agora, entretanto, a soldagem está sendo feita num processo avançado de cooperação do trabalho. (...) Cabe lembrar que essa unidade contraditória não elimina suas diferenças, ao contrário, aprofunda-as tornando cada um mais específico, porém, cada vez mais portador da característica geral de ambos. (...) Isso certamente aponta para a necessidade de compreendermos que a reforma agrária se faz no campo, mas se ganha na cidade (OLIVEIRA, 1991: 26-7). 


\section{Referências}

ABRAMOVAY, Ricardo. "Agricultura familiar e desenvolvimento territorial”. In Reforma Agrária - Revista da Associação Brasileira de Reforma Agrária nº1, vol. 28. jan/ago 1999.

ABRAMOVAY, Ricardo. Paradigmas do capitalismo agrário em questão. São Paulo; Rio de Janeiro: Editora Hucitec; ANPOCS, 1992.

CHAYANOV, Alexander V. The theory of peasant economy. Madison, Wis.: University of Wisconsin Press, 1986.

COUTINHO, Maurício Chalfin. "Incursões marxistas". Estud. av., São Paulo, v. 15,

n. 41,2001. Disponível em: <http://www.scielo.br/scielo.php?script=sci_arttext\&pid=S010340142001000100005\&lng=en\&nrm=iso $>$. Acesso em: 27 Abr 2008.

DEBORD, Guy. A sociedade do espetáculo. Rio de Janeiro: Contraponto, 2003.

GRAZIANO DA SILVA, José Graziano da. A nova dinâmica da agricultura brasileira. Campinas: Unicamp-IE, 1996.

GRAZIANO DA SILVA, José. O Novo Rural Brasileiro. Campinas - SP: IE/Unicamp, 2a ed, (Série Pesquisa, 1), 1999.

KAUTSKY, Karl. Questão agrária. Rio de Janeiro: Laemmert, 1968.

KROPOTKIN, Pedro. Campos, fabricas y talleres. Madrid, Jucar, 1978.

LEFEBVRE, Henri. O pensamento marxista e a cidade. S.1: Ulisses, 1972.

LEFEBVRE, Henri. De lo rural a lo urbano. Barcelona, Ediciones Península, 1971.

LENCIONI, Sandra. Agricultura e urbanização: a capitalização no campo e a transformação da cidade - Jardinópolis, o estudo de um lugar. Dissertação de Mestrado, FFLCH-USP, São Paulo, 1985.

LÊNIN, Vladimir Il'ich. Desenvolvimento do capitalismo na Rússia. São Paulo: Abril Cultural, 1982.

MARCOS, Valéria de. Comunidade Sinsei: (u)topia e territorialidade. Dissertação (Mestrado). São Paulo, 1996.

MARQUES, Marta Inez Medeiros. "O conceito de espaço rural em questão”. In: Terra Livre. São Paulo, ano 18, n. 19, p. 95-112, jul./dez. 2002.

MARQUES, Marta Inez Medeiros. Modo de vida camponês sertanejo e sua territorialidade no tempo das grandes fazendas e nos dias de hoje em Ribeira - PB. Dissertação (Mestrado). São Paulo, FFLCH-USP, 1994. 
MARTINS, José de Souza. A sociedade vista do abismo: novos estudos sobre exclusão, pobreza e classes sociais. Petrópolis: Vozes, 2003.

MARTINS, José de Souza. Expropriação e violência: a questão política no campo. São Paulo: Editora Hucitec, 1980.

MARTINS, José de Souza. Os camponeses e a política no Brasil. Petrópolis: Vozes, 1981.

MARTINS, José de Souza. Introdução crítica à sociologia rural. $2^{\mathrm{a}}$ ed., São Paulo: Hucitec, 1986.

MARTINS, José de Souza. O cativeiro da terra. São Paulo: Hucitec, 1998.

MARX, Karl. A Ideologia Alemã (i - Feuerbach). São Paulo: Grijalbo, 1977.

OLIVEIRA, Ariovaldo Umbelino de. A agricultura camponesa no Brasil. São Paulo, SP: Editora Contexto, 1991.

PINSKY, Jaime. As primeiras civilizações. São Paulo: Atual, 1987.

QUEIROZ, Maria Isaura Pereira de. "Dialética do rural e do urbano". In: BLAY, Eva Alterman (org.). A luta pelo espaço. Petrópolis [Brasil]: Editora Vozes, 1978.

QUEIROZ, Maria Isaura Pereira de. "Do rural e do urbano no Brasil". In: SZMERECSÁNYI, T.; QUEDA, O. Vida Rural e mudança social. $3^{\text {a }}$ ed., São Paulo: Ed. Nacional, 1979.

SANTOS, Milton. Técnica, espaço, tempo: globalização e meio técnico-científico informacional. São Paulo: Editora Hucitec, 1994.

SINGER, Paul Israel. Economia política da urbanização. $6^{\text {a }}$ ed., São Paulo: Brasiliense, 1979.

SUZUKI, Julio César. De povoado a cidade: a transição do rural ao urbano em Rondonópolis. Dissertação de Mestrado, São Paulo, FFCLH-USP, 1996.

VEIGA, José Eli da. Cidades imaginárias: o Brasil é menos urbano do que se calcula. Campinas, SP: Editora Autores Associados, 2002. 